\title{
GRAMÁTICAS E ENSINO DE LÍNGUA PORTUGUESA: ANÁLISE COMPARATIVA DA CLASSE DOS PRONOMES PESSOAIS
}

\section{GRAMMARS AND BRAZILIAN PORTUGUESE LANGUAGE TEACHING: COMPARATIVE ANALYSIS OF PERSONAL PRONOUNS WORD CLASS}

\author{
Maíra Avelar* \\ UESB
}

\section{Ana Claudia Oliveira Azevedo** Fapesb/UESB}

\begin{abstract}
Resumo: Neste artigo, abarcamos três estágios das Gramáticas no ensino de Língua Portuguesa. Tendo em vista demonstrar como operam diferentes materiais, realizamos uma análise comparativa da classe “pronomes pessoais” em uma Gramática Tradicional, um Livro Didático e uma Gramática Científica. Atrelamos essa análise à apresentação dos seguintes contextos: a instauração da NGB, a proposição do PNLD e a produção de gramáticas por linguistas. A discussão dos dados demonstrou que, do ponto de vista das definições, há uma consonância entre a Gramática Tradicional e o Livro Didático, ambos pautados pela NGB. Já na Gramática Científica, diferentes tipos de pronomes são agrupados e apresentados como integrantes de diferentes processos que ocorrem na língua. Do ponto de vista das funções, o Livro Didático, assim como a Gramática Científica, ilustra a importância do contexto para a compreensão do funcionamento da classe de palavra em análise. Por sua vez, a Gramática Tradicional evidencia seu caráter prescritivista, pois, além de pautar-se majoritariamente em exemplos literários descontextualizados, apresenta usos dos pronomes considerados "errados". Em conclusão, apontamos que não há um método ou manual gramatical definitivos para o ensino de Língua Portuguesa, mas sim obras que se complementam e podem ser utilizadas em conjunto para esse fim.
\end{abstract}

Palavras-chave: Ensino de Língua Portuguesa. Gramática Científica. Gramática Tradicional. Livro didático.

\begin{abstract}
In this paper, we cover three stages of Grammars in Brazilian Portuguese Language teaching. In order to demonstrate how different materials operate, we perform a comparative analysis of the class "personal pronouns" in a Traditional Grammar, a Textbook and a Scientific Grammar. We associate this analysis to the presentation of the following contexts: the establishment of Brazilian Grammatical Nomenclature (NGB), the proposition of the Textbook National Program (PNLD) and the production of grammars by linguists. The data discussion showed that, from the point of view of definitions, there is a consonance between Traditional Grammar and the Textbook, both guided by the NGB. In Scientific
\end{abstract}

\footnotetext{
*Doutora em Linguística e Língua Portuguesa. E-mail: mairavelar@uesb.edu.br.

** Mestranda em Linguística (PPGLin/UESB). E-mail: 98anaclaudia@gmail.com.
} 
Grammar, on its turn, different types of pronouns are grouped and presented as members of different processes that occur in the language. From the point of view of functions, the Textbook, as well as the Scientific Grammar, illustrate the importance of the context for understanding the functioning of the word class under analysis. In its turn, Traditional Grammar demonstrates its prescriptive character, because, in addition to being primarily based on decontextualized literary examples, it presents uses of pronouns that are considered "wrong”. In conclusion, we highlight that there is no definitive grammatical method or manual for Brazilian Portuguese Language teaching, but rather works that complement each other and can be used together for this purpose.

Keywords: Brazilian Portuguese Language Learning. Scientific Grammar. Traditional Grammar. Textbook.

\section{INTRODUÇÃO}

O caráter polissêmico do termo "gramática” ativa desde acepções mais concretas, como “manual” ou “livro”, até as experiências com a disciplina de Língua Portuguesa na escola, que, pelo fato de adotar uma perspectiva normalmente atrelada à Gramática Tradicional, conduz a uma acepção de "gramática” como um conjunto de regras prescritivas. Nas últimas décadas, sobretudo no âmbito dos estudos linguísticos, há acepções mais amplas, ligadas à ideia de funcionamento do sistema linguístico, provenientes de análises mais aprofundadas por parte de estudiosos que se dedicam ao estudo e à pesquisa sobre a língua.

Segundo Savioli (2014), se tomarmos como referência o ensino de Língua Portuguesa no Brasil por volta dos últimos cinquenta anos, é possível identificar três estágios distintos nesse percurso: o primeiro estágio pode ser estabelecido entre meados de 1960 e fins de 1970. Nesse período, “gramática” correspondia a uma “matéria escolar”. Conforme o autor (2014), aprender a língua correspondia a aprender descrições da língua vernácula e suas prescrições. Dessa forma, a regra era apenas uma: o que não se enquadrasse nos parâmetros prescritivos da língua vernácula era tido como deformação, decadência, ou mesmo erro, deficiência. Embora Savioli (2014) trate desse período como superado no ensino de gramática, é possível notar, nos dias atuais, a correspondência entre "gramática” e "disciplina escolar”, uma vez que aulas de gramática ainda ocupam boa parte das aulas de Língua Portuguesa, assim como boa parte dos livros didáticos.

O segundo estágio, conforme propõe Savioli (2014), corresponde ao início da década de 1980 e fins da de 1990. Com os cursos de Linguística já implementados em algumas instituições de ensino superior e com professores capacitados, houve um movimento de análise crítica das gramáticas tradicionais, apontando suas limitações e fazendo propostas de superação. Nesse sentido, observa-se uma mudança nas concepções de "gramática” e as repercussões decorrentes dessa alteração nas ações escolares. Porém, segundo Savioli (2014), o que de fato se verificou foi um descompasso entre as reformulações dos modelos teóricos das gramáticas e a sua aplicação nas práticas pedagógicas no Brasil, pois, apesar de os professores do Ensino Básico demonstrarem um desejo de mudança, a capacidade de compreender as novas propostas e, sobretudo, de encontrar estratégias didáticas eficazes para colocá-las em uso foi demorada. Nota-se, ainda hoje, essa dificuldade de transposição didática de modelos teóricos: por um lado, tem-se acesso a novas visões de gramática nos cursos de Letras; por outro, o exercício de levar esse conteúdo para as turmas de Ensino Básico revela-se difícil e desafiador. 
Já o terceiro estágio, de acordo com Savioli (2014), que se estende do início dos anos 2000 até a atualidade, consolida o acolhimento dos fundamentos teóricos das gramáticas de base linguística por parte dos responsáveis pelo ensino da Língua Portuguesa. “Gramática” passa, então, a corresponder, conforme Savioli (2014, p. 44), ao “conjunto de leis responsáveis pelas regularidades geradoras de sentidos e de efeitos de sentido”. Nessa perspectiva, o ensino da gramática pauta-se por privilegiar o sentido, tanto na dimensão semântica quanto na dimensão pragmática. Ainda segundo Savioli (2014), a explicitação da importância dos valores sociais para o sucesso das estratégias linguísticas revela as implicações recíprocas entre língua e sociedade. Sendo assim, para a produção de textos orais ou escritos, não basta conhecer apenas o código: é preciso conhecer também a cultura dos participantes da interlocução. Apesar de documentos como os Parâmetros Curriculares Nacionais (PCN, BRASIL, 1999) e a Base Nacional Comum Curricular (BNCC, BRASIL, 2018) incentivarem o trabalho com a diversidade linguística, o papel de "guardião da norma” ainda é desempenhado e cobrado do professor de língua materna.

Com vistas a abarcar esses três estágios do percurso gramatical no ensino e aprendizagem de Língua Portuguesa, bem como a ilustrar como operam diferentes materiais dedicados à discussão gramatical, temos como objetivo realizar uma investigação comparativa do tratamento da classe gramatical pronome e, mais especificamente, do pronome pessoal em uma Gramática Tradicional, um Livro Didático e uma Gramática Científica. A gramática tradicional selecionada para análise é a Nova Gramática do Português Contemporâneo, escrita pelo brasileiro Celso Cunha e pelo português Lindley Cintra e publicada pela primeira vez em 1985. O livro didático utilizado é intitulado Português: Ensino Médio, escrito por José de Nicola e destinado ao segundo ano do Ensino Médio. A gramática científica na qual nos baseamos é a Gramática de Usos do Português, escrita pela linguista Maria Helena de Moura Neves. O material escolhido para análise faz parte da seleção de materiais da disciplina "Linguística: gramáticas científicas e pedagógicas”, na qual são discutidas diferentes teorias gramaticais e materiais didáticos voltados ao ensino de Língua Portuguesa. Especificamente, a categoria pronome é alvo de diversas abordagens, tanto do ponto de vista do paradigma tradicional, quanto do ponto de vista de paradigmas científicos da Linguística.

\section{A GRAMÁTICA TRADICIONAL, O LIVRO DIDÁTICO E A GRAMÁTICA CIENTÍFICA EM CONTEXTOS DE ENSINO DA LÍNGUA PORTUGUESA}

Pretendemos apresentar, na sequência, uma análise comparativa da classe de palavras pronome pessoal nos materiais de referência citados anteriormente, uma vez que cada um deles representa um período distinto do histórico do ensino de gramática proposto por Savioli (2014). Além disso, a gramática de Cunha e Cintra (2001) é citada nas referências do livro didático de De Nicola (2005). Da mesma maneira, para construir sua abordagem a respeito dos pronomes, Neves (2000) parte da categorização proposta pelas Gramáticas Tradicionais e, a partir dessa abordagem, demonstra novas possibilidades de análise de cunho funcionalista. Abordaremos, então, alguns aspectos da Nomenclatura Gramatical Brasileira (NGB) para, na sequência, procedermos à análise comparativa proposta. 


\section{A NOMENCLATURA GRAMATICAL BRASILEIRA E O ENSINO DE LÍNGUA PORTUGUESA: ABORDAGEM DA CLASSE DE PALAVRAS PRONOME PESSOAL NA GRAMÁTICA TRADICIONAL}

Segundo Henriques (2009), em 1958, quando da proposição do Anteprojeto de simplificação e unificação da Nomenclatura Gramatical Brasileira, havia, no ensino da Língua Portuguesa no Brasil, uma enorme profusão de termos gramaticais e um total conflito no emprego desses termos. Essa situação, alvo da preocupação de filólogos e autoridades pedagógicas, prejudicava o estudante do curso médio, diversas vezes enredado por não saber decifrar a variedade de códigos terminológicos que lhe eram impostos e cobrados em provas e concursos. A partir dos esforços de filólogos lotados no Colégio Pedro II, no Rio de Janeiro, foi elaborada e instaurada a Portaria 36/1959, estabelecendo a NGB, que passou, então, a orientar a produção de materiais gramaticais (BRASIL, 1958).

Em 1985, ao lançarem sua gramática conjunta, Celso Cunha e Lindley Cintra reiteram a importância de um tratamento também conjunto acerca da descrição do português. Segundo os autores (2001, p. XVIII), era necessário apresentar uma descrição do português contemporâneo que considerasse, simultaneamente, “as diversas normas vigentes dentro do seu vasto domínio geográfico (principalmente admitidas como padrão em Portugal e no Brasil)”.

No caso específico dos pronomes, em edição mais recente de sua gramática, Cunha e Cintra (2001) definem-nos como classes que desempenham funções equivalentes às dos elementos nominais na oração. Segundo os gramáticos, os pronomes podem desempenhar duas funções: 1) representar um substantivo (pronomes substantivos) ou 2) acompanhar um substantivo, determinando-lhe a extensão do significado (pronomes adjetivos). Cunha e Cintra (2001) citam um exemplo de cada função, retirado de obras literárias. Os gramáticos pontuam que há seis tipos de pronomes: pessoais, possessivos, demonstrativos, relativos, interrogativos e indefinidos.

Os pronomes pessoais, conforme Cunha e Cintra (2001), possuem três características:

a. Denotam três pessoas gramaticais, tendo a capacidade de indicar quem fala ( $1^{\mathrm{a}}$ pessoa), com quem se fala ( $2^{\mathrm{a}}$ pessoa) ou de quem se fala ( $3^{\mathrm{a}}$ pessoa);

b. Na $3^{\mathrm{a}}$ pessoa, podem representar uma forma nominal expressa anteriormente;

c. Variam de forma, segundo a função que desempenham na oração: podem ser retas (quando forem sujeito da oração) ou oblíquas (quando empregadas como objeto direto ou indireto); e, segundo a acentuação que recebem na palavra, podendo ser tônicas ou átonas.

Os autores apresentam o seguinte quadro para ilustrar as diferentes formas do pronome pessoal: 
Quadro 1: Apresentação dos pronomes pessoais na Gramática de Cunha e Cintra (2001)

\begin{tabular}{|c|c|c|c|c|}
\hline & & \multirow{2}{*}{$\begin{array}{c}\text { PRONOMES } \\
\text { PESSOAIS } \\
\text { RETOS } \\
\end{array}$} & \multicolumn{2}{|c|}{$\begin{array}{c}\text { PRONOMES PESSOAIS } \\
\text { OBLÍQUOS NÃO REFLEXIVOS }\end{array}$} \\
\hline & & & ÁTONOS & TÔNICOS \\
\hline Singular & $\begin{array}{l}1^{\mathrm{a}} \text { pessoa } \\
2^{\mathrm{a}} \text { pessoa } \\
3^{\mathrm{a}} \text { pessoa }\end{array}$ & $\begin{array}{l}\text { Eu } \\
\text { tu } \\
\text { ele, ela } \\
\end{array}$ & $\begin{array}{l}\text { Me } \\
\text { te } \\
\text { o, a, lhe } \\
\end{array}$ & $\begin{array}{l}\text { mim, comigo } \\
\text { ti, contigo } \\
\text { ele, ela }\end{array}$ \\
\hline Plural & $\begin{array}{l}1^{\mathrm{a}} \text { pessoa } \\
2^{\mathrm{a}} \text { pessoa } \\
3^{\mathrm{a}} \text { pessoa }\end{array}$ & \begin{tabular}{|l} 
Nós \\
vós \\
eles, elas
\end{tabular} & $\begin{array}{l}\text { Nos } \\
\text { vos } \\
\text { os, as, lhes } \\
\end{array}$ & $\begin{array}{l}\text { nós, convosco } \\
\text { vós, convosco } \\
\text { eles, elas }\end{array}$ \\
\hline
\end{tabular}

Fonte: Cunha e Cintra (2001, p. 277)

O Quadro 1, apresentado por Cunha e Cintra (2001), divide os pronomes pessoais em singular e plural, sendo cada uma dessas categorias divididas em $1^{\mathrm{a}}, 2^{\mathrm{a}}$ e $3^{\mathrm{a}}$ pessoas. Além disso, os pronomes pessoais são divididos em retos e oblíquos não reflexivos, sendo estes últimos subdivididos em átonos e tônicos. Os autores (2001) comentam a respeito de algumas regras de uso dos pronomes, dentre elas, as diferentes formas assumidas pelo pronome oblíquo da $3^{\mathrm{a}}$ pessoa, em posição enclítica, a depender da terminação verbal. Segundo os gramáticos, quando o pronome oblíquo de $3^{\mathrm{a}}$ pessoa vem antes do verbo, apresenta-se nas formas $o, a$, os, as.

Cunha e Cintra (2001) explicam, também, que, em posição de ênclise - quando o pronome está após o verbo - , sua forma varia de acordo com a terminação do verbo: 1) Se a forma verbal terminar em vogal ou ditongo oral, usa-se $o, a$, os, as; 2) Quando a forma verbal acaba em $-r$, $-s$ ou $-z$, essas consoantes são suprimidas e o pronome é empregado nas modalidades lo, la, los, las. Essas mesmas formas são usadas após o designativo eis ou aos pronomes nos e vos; 3) Quando a forma verbal termina em ditongo nasal, são empregadas as modalidades no, na, nos, nas. Eles fazem, também, uma observação acerca da evolução das formas antigas do pronome oblíquo objeto direto do latim ao português, como, por exemplo: Fazer-lo>fazello > fazê-lo e Fazem-lo>fazem-no. De acordo com Cunha e Cintra (2001), ainda, no futuro do presente e futuro do pretérito, o pronome oblíquo não pode vir depois do verbo, em forma de ênclise, devendo-se usar a mesóclise nessas situações.

Na seção seguinte, Cunha e Cintra (2001) apresentam os pronomes reflexivos e recíprocos. Segundo eles, os primeiros ocorrem "quando o objeto direto ou indireto representa a mesma pessoa ou a mesma coisa que o sujeito do verbo” (CUNHA; CINTRA, 2001, p. 280). Os pronomes reflexivos apresentam, para a $3^{\text {a }}$ pessoa, as formas próprias se, si e consigo, ao passo que, nas demais pessoas, são usados os pronomes oblíquos me, te, nos e vos. Quando, nas pessoas do plural, indica-se reciprocidade da ação, o pronome é classificado como recíproco.

Os gramáticos comentam que o fato de as formas dos pronomes reflexivos serem as mesmas dos pronomes recíprocos pode gerar ambiguidade, a qual pode ser desfeita com a adição de termos reforçativos especiais. Tomando como exemplo a frase "Joaquim e António enganaram-se”, Cunha e Cintra (2001) mostram que, para marcar a ação reflexiva, pode-se acrescentar expressões reforçativas, conforme a pessoa gramatical, como a mim mesmo, a ti mesmo, a si mesmo etc. ("Joaquim e António enganaram-se a si mesmos"). Para marcar a ação recíproca, por sua vez, podem ser adicionados termos como um ao outro, uns aos outros, 
entre si ("Joaquim e António enganaram-se entre si/Joaquim e António enganaram-se um ao outro") ou advérbios como reciprocamente ou mutuamente (“Joaquim e António enganaram-se mutuamente”). Eles mencionam, ainda, que, para marcar reciprocidade, há uma frequência no uso de formas verbais derivadas com o prefixo entre-. Como exemplo, citam: "Marido e mulher entreolharam-se” (NEMÉSIO [1944], p. 363 apud CUNHA; CINTRA, 2001, p. 281, destaques dos autores).

Em seguida, há uma seção a respeito do emprego dos pronomes retos, que, conforme Cunha e Cintra (2001), podem exercer as funções de sujeito, predicativo do sujeito e vocativos (no caso de tu e vós). Os autores discorrem a respeito da omissão dos pronomes sujeitos na língua portuguesa, ocasionada pelo fato de as desinências verbais serem suficientes para indicar a pessoa e o número do sujeito. Segundo os gramáticos (2001), a presença do pronome sujeito ocorre em situações em que se quer enfatizar a pessoa do sujeito, para opor pessoas diferentes ou quando a forma verbal é ambígua (para $1^{\mathrm{a}}$ e $3^{\mathrm{a}}$ pessoas do singular). Essa afirmação vai ao encontro de estudos linguísticos que consideram o português como uma língua de sujeito nulo (cf. FIGUEIREDO SILVA, 1996). Entretanto, trabalhos mais recentes (cf. CASTILHO, 2010) têm mostrado que o Português Brasileiro (PB) está se tornando uma língua de sujeito preenchido, uma vez que o quadro flexional dos pronomes no PB tem sofrido redução, o que faz necessário o preenchimento do sujeito na oração.

Cunha e Cintra (2001), na seção extensão de emprego dos pronomes retos, comentam a respeito de algumas particularidades, como o chamado plural de modéstia, em que nós é empregado com valor de $e u$, semelhante ao plural de majestade, que costumava ser usado pelos reis de Portugal e é usado até hoje pelos ocupantes de altos cargos da Igreja para designar a sua grandeza. Outros usos especiais citados são a fórmula de cortesia, na qual se usa a $3^{\text {a }}$ pessoa pela $1^{\mathrm{a}}$, e $o$ vós de cerimônia, utilizado geralmente em discursos enfáticos para se dirigir a um auditório qualificado. Os autores (2001) reconhecem que o pronome vós está quase extinto na linguagem corrente do Brasil e de Portugal, mas assumem, também, que tal pronome pode ser usado, em linguagem literária, para expressar apreço social, além de ser a forma usada por católicos para se dirigirem a Deus.

Além disso, conforme Cunha e Cintra (2001), o realce do pronome sujeito ocorre por meio do uso de palavras como mesmo e próprio ou da expressão é que, logo após o pronome sujeito. Os autores acrescentam que é necessário ter modéstia ao usar o pronome $e u$, utilizando-o em último lugar quando o sujeito for composto, como forma de civilidade. Na seção equívocos e incorreções, Cunha e Cintra (2001) apresentam algumas regras de como [não] usar os pronomes pessoais. Dentre essas regras, destacam que se deve evitar o uso de ele como objeto direto, apesar de seu uso ser comum na fala vulgar e familiar do Brasil. Vê-se, com isso, que os gramáticos tradicionais não estão preocupados em descrever a língua como ela é, visto que, mesmo reconhecendo seu funcionamento, preocupam-se em mostrar como a língua deveria ser.

É válido ressaltar que, ao longo de todas as seções, ao adicionarem novas informações, os autores apresentam exemplos para ilustrar a explicação. Os exemplos elencados por Cunha e Cintra (2001) são retirados de obras literárias, quando não são frases imaginadas e descontextualizadas ou, simplesmente, palavras isoladas. Segundo Anjos (2016), o período helenístico marcou profundamente o modo de produção de gramáticas normativas, no que diz respeito, por exemplo, ao exclusivismo do corpus literário. Consequentemente, conforme aponta Neves 
(2002), “gramática”, nesse contexto, limita-se à língua escrita, especialmente à língua literária do passado, com vistas à preservação da “pureza” da língua grega. Entretanto, convém sinalizar que, se, no contexto da Antiguidade Clássica, essa acepção de gramática fazia sentido, há que se avaliar a pertinência ou não dessa acepção no contexto atual.

\section{O PNLD E AS POLÍTICAS NACIONAIS DE UNIVERSALIZAÇÃO DO USO DO LIVRO DIDÁTICO: ABORDAGEM DOS PRONOMES PESSOAIS NO LIVRO DIDÁTICO}

A universalização da escola no Brasil é relativamente recente: segundo Silva (2012), nos anos 1960, o acesso democrático à escola levou a uma grande expansão da rede pública de ensino no Brasil. Especificamente, com a redemocratização do país, em 1985, foi criado o Programa Nacional do Livro Didático (PNLD), um programa federal de distribuição gratuita de Livros Didáticos a estudantes de escolas públicas brasileiras. O Programa tem por objetivo “universalizar, gradativamente, o uso do livro didático” (BRASIL, 2002) e funciona da seguinte maneira (SILVA, 2012): uma equipe de pareceristas, formada por professores de Instituições Públicas de Ensino Superior e, mais recentemente, por alguns professores do Ensino Básico, produz um catálogo de resenhas das coleções de livros aprovadas para participar das edições trienais do Programa.

Conforme explica Silva (2012), os livros, analisados e escolhidos pelos professores de cada escola, são encomendados pelo MEC junto às editoras e distribuídos gratuitamente aos estudantes. Cada estabelecimento de ensino pode solicitar novos títulos ou manter a escolha para uma nova compra a cada intervalo de três anos. O Programa Nacional do Livro do Ensino Médio (PNLEM), por sua vez, foi implementado em 2004: “A Resolução nº 38 do FNDE, que criou o programa, define o atendimento, de forma progressiva, aos alunos das três séries do ensino médio de todo o Brasil” (BRASIL, 2004). Em decorrência da implementação do PNLEM, foram elaborados, assim como no PNLD, Catálogos com avaliações dos Livros Didáticos aprovados por pareceristas.

O Livro Didático Português: Ensino Médio vol. 2, escrito por José de Nicola (2005), consta no Catálogo do PNLEM de 2009. Segundo o parecer apresentado na síntese avaliativa sobre o livro, o manual cumpre, de maneira apropriada, “o desafio de formar competentes leitores e produtores de unidades de sentido/texto”. Além disso, “a obra oferece material representativo de diferentes gêneros textuais (literários e não-literários) e tendências artísticas” (BRASIL, 2009, p. 78). Destacamos que uma ressalva geral é apresentada: "a coleção se beneficiaria da exploração de textos motivadores, que introduzissem a reflexão sobre os conteúdos a serem posteriormente sistematizados na unidade” (BRASIL, 2009, p. 79).

Tal como descrito no Catálogo, o segundo volume da série, dentre outros conteúdos listados, "centra-se na descrição das classes de palavras [...]” (BRASIL, 2009, p. 80). O sexto capítulo do Livro Didático apresenta o conteúdo referente ao pronome. O autor inicia o capítulo com uma tirinha de Luis Fernando Verissimo, apresentada a seguir: 
Figura 1: Tirinha apresentada no Livro Didático de De Nicola (2005)

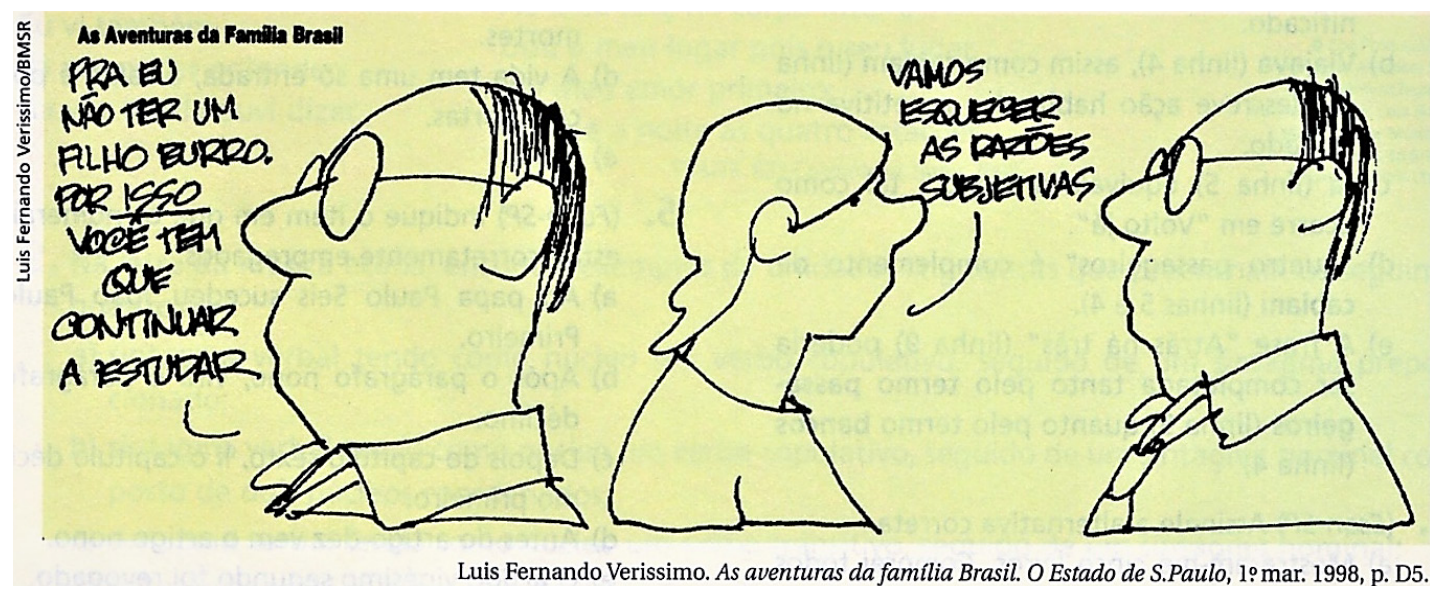

Fonte: De Nicola (2005, p. 76)

A tirinha não recebe, inicialmente, nenhum comentário por parte de De Nicola. Logo após a tirinha, é apresentada a origem da palavra pronome — vem do latim pronomen, que significa que está no lugar do nome. Com base nisso, segundo o autor (2005), pode-se deduzir uma das funções básicas do pronome: substituir um nome, carregando seu conteúdo semântico. Em seguida, De Nicola (2005) utiliza os pronomes da tira para exemplificar o valor semântico do nome que os pronomes mantêm. É importante destacar que o autor leva em consideração o gênero textual em que o pronome aparece, afirmando que, na tira, há elementos verbo-visuais que auxiliam na referenciação, marcada pelos pronomes.

Ele comenta que, em outros gêneros, a referência dos pronomes poderia ser identificada por meio do contexto situacional. Assim, afirma que "só pela referenciação podemos decifrar o conteúdo semântico de um pronome” (DE NICOLA, 2005, p. 76). Convém salientar que o autor não define o termo referenciação. Em seguida, De Nicola (2005, p. 77) define pronome como: "palavra que substitui ou acompanha elementos presentes no texto ou na situação do enunciado, indicando sua posição em relação às pessoas do discurso ou mesmo situando-os no espaço e no tempo". Para ilustrar essa definição, o autor apresenta exemplos de frases criadas por ele e, também, de uma frase da literatura contemporânea e explica quais termos daquela frase são pronomes e porque o são, conforme demonstrado a seguir, numa reprodução fiel ao Livro (DE NICOLA, 2005, p. 77):

Na frase de Clarice Lispector:

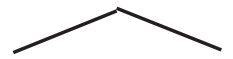

No dia em que eu conseguir uma forma tão pobre como eu o sou por dentro (...). dentro...)

o pronome o substitui o adjetivo pobre (... uma forma tão pobre como eu sou pobre por

Após discutir esses exemplos, De Nicola (2005) afirma que os pronomes são morfologicamente variáveis, visto que admitem flexão de pessoa, gênero e número. Essa variação, apesar de aparecer nos quadros de pronomes, não é explicitada na gramática tradicional de Cunha e Cintra (2001). O autor aponta, também, que o pronome pode ser classificado como 
substantivo - quando substitui o nome e desempenha funções típicas do substantivo (núcleo do sujeito, do objeto, do vocativo etc.) — ou adjetivo — quando acompanha o substantivo e desempenha funções típicas de adjetivo (adjunto adnominal). Ele rememora as três pessoas do discurso (primeira pessoa — aquela que fala ou falante — , segunda — aquela com quem se fala ou interlocutor - e terceira - aquela de quem se fala ou referente), a fim de que se compreenda melhor a definição apresentada anteriormente.

O autor acrescenta que o pronome e o substantivo são bem diferentes, apesar de aquele poder assumir o papel deste. Ele explica que "o pronome expressa um ser apenas quando inserido num contexto [...], ou seja, fora de contexto, o pronome é desprovido de conteúdo semântico” (DE NICOLA, 2005, p. 78). Em seguida, o autor apresenta o exemplo a seguir, reproduzido de maneira fiel ao Livro, a fim de ilustrar a importância do contexto (DE NICOLA, 2005, p. 77-78):

Figura 2: Exemplo apresentado no Livro Didático de De Nicola (2005)

Mas o rabo, a tromba, tudo o confunde e ele não consegue totalizar a ideia

"O que isso tem a ver com Elefante? O título é uma homenagem ao diretor Alan Clarke, que fez um filme homônimo sobre a violência religiosa na Irlanda. Nele se conta, como uma parábola, a história do cego que quer saber o que é um elefante. Trazem o bicho e o cego esquadrinha o animal com as mãos, tentando desvendar, por meio do tato. o segredo da sua forma. Mas o rabo, a tromba, tudo confunde e

não consegue totalizar a ideia. A soma das pequenas partes não lhe permite resolver o enigma."

O Estado de S. Paulo, 2 abr. 2004, p. D1.

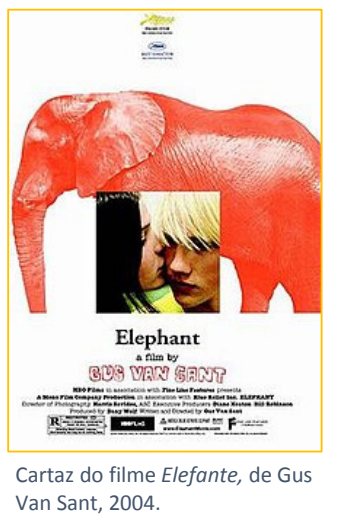

Agora sabemos que os pronomes o e ele substituem "o cego".

Fonte: De Nicola (2005, p. 77-78)

Ao apresentar o exemplo em questão, o autor (2005) promove, mesmo que indiretamente, uma superação da crítica às frases descontextualizadas que, muitas vezes, a Gramática Tradicional e os Livros Didáticos apresentam. Na sequência, De Nicola (2005) apresenta um quadro com as seis espécies de pronomes, que são classificados conforme a referência que fazem. Nesse quadro, o autor apresenta a divisão dos pronomes em pessoal, possessivo, demonstrativo, relativo, indefinido e interrogativo, bem como uma breve definição de cada um. A seção seguinte diz respeito ao pronome pessoal, definido como "aquele que indica as pessoas do discurso" (DE NICOLA, 2005, p. 78). De acordo com o autor, essa espécie de pronome apresenta variações de gênero, número e pessoa, além de variações de forma - definida pela função exercida pelo pronome na oração, podendo ser reto ou oblíquo. De Nicola (2005, p. 78) apresenta, então, um quadro com os pronomes pessoais: 
Quadro 2: Apresentação dos pronomes pessoais no Livro Didático de José de Nicola

\begin{tabular}{|c|c|c|c|c|}
\hline \multirow{2}{*}{ NÚMERO } & \multirow{2}{*}{ PESSOA } & \multirow{2}{*}{$\begin{array}{c}\text { PRONOMES } \\
\text { RETOS }\end{array}$} & \multicolumn{2}{|c|}{ PRONOMES OBLÍQUOS } \\
\hline & & & ÁTONOS & TÔNICOS \\
\hline Singular & $\begin{array}{l}\text { Primeira } \\
\text { segunda } \\
\text { terceira }\end{array}$ & $\begin{array}{l}\text { Eu } \\
\text { tu } \\
\text { ele, ela }\end{array}$ & $\begin{array}{l}\text { Me } \\
\text { te } \\
\text { o, a, lhe, se }\end{array}$ & $\begin{array}{l}\text { mim, comigo } \\
\text { ti, contigo } \\
\text { ele, ela, si, consigo }\end{array}$ \\
\hline Plural & $\begin{array}{l}\text { Primeira } \\
\text { segunda } \\
\text { terceira }\end{array}$ & $\begin{array}{l}\text { Nós } \\
\text { vós } \\
\text { eles, elas }\end{array}$ & $\begin{array}{l}\text { Nos } \\
\text { vos } \\
\text { os, as, lhes, se }\end{array}$ & $\begin{array}{l}\text { nós, convosco } \\
\text { vós, convosco } \\
\text { eles, elas, si, consigo }\end{array}$ \\
\hline
\end{tabular}

Fonte: De Nicola (2005, p. 78)

No Quadro 2, José de Nicola (2005) classifica os pronomes pessoais por número e pessoa, além de apresentar as divisões em pronomes retos e oblíquos, subdividindo esses últimos em átonos e tônicos. A divisão proposta por De Nicola (2005) é bastante semelhante ao Quadro 1, elaborado por Cunha e Cintra (2001). Após definir os pronomes pessoais, o autor (2005) aborda outros tipos de pronome e apresenta um exercício com questões de processos seletivos. Nas questões relacionadas a pronome pessoal, há perguntas sobre as pessoas do discurso, sobre o uso inclusivo e exclusivo do pronome da primeira pessoa do plural e sobre o uso de pronomes oblíquos, o que não é explicado na seção anterior aos exercícios. Consideramos, portanto, que o breve tópico dedicado à definição dos pronomes pessoais não é suficiente para que o aluno responda satisfatoriamente aos exercícios.

Em outra seção, o pronome pessoal na frase, De Nicola (2005) reitera que os pronomes pessoais sempre exercem funções substantivas, seja como sujeito ou predicativo do sujeito (pronomes do caso reto) ou como objeto (pronomes do caso oblíquo). A seguir, ele apresenta um trecho de música e, a partir dela, mostra as diferentes funções sintáticas que os pronomes pessoais exercem naquele contexto. Depois disso, o autor explica que os pronomes oblíquos podem ser tônicos ou átonos, sendo aqueles precedidos por preposição, ao passo que estes, não. Com base nessas informações, De Nicola (2005) apresenta um novo quadro dos pronomes pessoais, dessa vez divididos por função sintática desempenhada na frase, e comenta que há uma exceção: o pronome oblíquo exerce a função de sujeito em orações reduzidas como exigiram-lhe sair. Ele relata, também, que, na linguagem coloquial, os pronomes retos de $3^{\text {a }}$ pessoa são muito comumente usados para indicar o objeto direto. Nesse momento, o autor não faz nenhuma observação a respeito de o uso coloquial ser errado ou correto.

Em seguida, De Nicola (2005) apresenta o tópico para mim ou para eu?, no qual explica que, quando o pronome for sujeito do verbo da oração reduzida de infinitivo, deve-se usar eu e não mim, visto que o pronome não está sendo selecionado pela preposição, e sim pelo verbo subsequente. O autor volta a abordar a função substantiva dos pronomes pessoais e comenta que, na língua coloquial, é comum o uso de sintagmas nominais com referência genérica, como a pessoa ou o cara, que exercem funções parecidas com as dos pronomes pessoais. Ele também cita a expressão a gente, que, além de ser uma referência genérica, pode indicar as pessoas do discurso. 
Na seção seguinte, colocação dos pronomes, De Nicola (2005) apresenta e define a ênclise, a próclise e a mesóclise, porém, não detalha as regras sobre seus usos. O autor comenta novamente sobre outras espécies de pronomes — fornece mais detalhes, assim como faz com os pronomes pessoais - e, em seguida, retoma os pronomes pessoais no tópico o caráter fórico dos pronomes pessoais. Nessa seção, a última que trata dos pronomes dessa espécie, ele comenta que a referência do pronome pode se dar de forma (i) situacional — fora do texto, também chamada de extralinguística ou exofórica — ou (ii) contextual — dentro do texto, também chamada de endofórica. Essa discussão sobre foricidade é realizada nas Gramáticas de cunho linguístico, a exemplo da Gramática de Usos do Português (NEVES, 2000).

De Nicola (2005) apresenta um exemplo para demonstrar essas duas formas de referência e acrescenta que "quando a referência é textual, o caráter fórico dos pronomes está também a serviço da articulação e da coesão do texto” (DE NICOLA, 2005, p. 99). Por meio desse comentário, o autor demonstra que os pronomes - assim como qualquer outra classe de palavras - não correspondem a meros componentes de frases, mas, sim, de textos, produzidos e circulantes na sociedade. Assim, o livro didático demonstra a funcionalidade da classe de palavras, não se atendo somente a regras prescritivas.

\section{A IMPLEMENTAÇÃO DA LINGUÍSTICA COMO DISCIPLINA E A PRODUÇÃO GRAMATICAL DE LINGUISTAS: O PRONOME PESSOAL NA GRAMÁTICA CIENTÍFICA}

A partir da década de 1960, a Linguística passou a ser implementada como disciplina em cursos de Ensino Superior no Brasil. Após a década de 1970, consolidaram-se diversos projetos coletivos de mapeamento de variedades linguísticas do PB. A partir desse período, a construção e consolidação de corpora eletrônicos viabilizou o acesso dos linguistas a usos da variedade culta ${ }^{1}$ da Língua Portuguesa em diferentes contextos. Consequentemente, foram criados subsídios para sustentar o conceito de "norma” como o uso reiterado de construções gramaticais. Sendo assim, estudos baseados em corpora podem legitimar usos ou mesmo desautorizar “erros” definidos de maneira arbitrária.

Segundo Savioli (2014), duas condições favoreceram a produção e circulação, bem como a aceitação de diversas obras gramaticais inovadoras ao mesmo tempo. A primeira delas corresponde à revisão epistemológica dos termos língua/linguagem, acessível à competência interpretativa dos professores de Língua Portuguesa, atendendo à demanda desses educadores por novos modelos de abordagem da língua nas gramáticas. A segunda corresponde a uma readequação, por parte das Gramáticas Científicas, das finalidades da língua, colocando em proeminência a importância dos contextos comunicativos e da construção de sentidos. Conforme aponta o autor (2014, p. 44), “é extensa, na verdade inumerável, a lista de benefícios que essa coleção de gramáticas trouxe para as práticas pedagógicas voltadas para o ensino de português”.

Especificamente, a Gramática de Usos do Português, de autoria de Maria Helena de Moura Neves (2000), possui um caráter descritivo, uma vez que parte de usos linguísticos reais para apresentar as regras que estão em funcionamento no PB. A autora (2000) considera

\footnotetext{
${ }^{1}$ Neste contexto, a expressão “variedade culta” diz respeito à norma urbana de prestígio, tal como proposto por projetos coletivos, como o NURC.
} 
o texto como unidade maior de funcionamento e, a partir disso, descreve o uso de elementos da língua, os quais contribuem para a construção de sentidos. Além disso, em confronto à posição de manuais de gramática tradicional, que, conforme mencionamos anteriormente, valem-se de exemplos literários ou mesmo de exemplos inventados para abarcar as definições estabelecidas, Neves (2000) propõe-se a descrever os “usos linguísticos”. A autora considera a avaliação dos usos como objeto e como meta de gramáticas que considerem os componentes da interação comunicativa.

Neves (2000) parte da nomenclatura tradicional das classes de palavras por questões didáticas, porém, apresenta uma nova divisão para elas, baseando-se nos “processos que dirigem a organização dos enunciados para obtenção do sentido do texto” (NEVES, 2000, p. 13), quais sejam, predicação, referenciação, quantificação e indefinição. O pronome pessoal, por exemplo, é apresentado na seção A referenciação situacional e textual: as palavras fóricas, junto com o artigo definido, o pronome possessivo e o pronome demonstrativo. Por isso, não há uma definição de pronome nessa Gramática. Já na apresentação da obra, Neves (2000) comenta que os pronomes pessoais são vistos tradicionalmente como meros substitutos do nome.

Indo de encontro a essa definição, a autora explicita algumas particularidades do pronome pessoal, no nível da oração, do sintagma e do texto. No nível da oração, segundo ela, o pronome pessoal é, de fato, parte da mesma esfera do nome, porém não é capaz de apresentar uma descrição do referente, por exemplo. Já no nível do sintagma, esse item funcionaria como um sintagma nominal, podendo ser considerado substituto do nome. No nível do texto, por fim, há atuação somente do pronome de $3^{\mathrm{a}}$ pessoa, exceto em textos com discurso direto, e, além disso, verifica-se uma diferença entre o pronome pessoal, que atua como referenciador textual, e o nome, que, geralmente, é o referente.

A seção específica para o pronome pessoal constitui a Parte II da gramática, que, como informado anteriormente, é intitulada de a referenciação situacional e textual: as palavras fóricas. Neves (2000) apresenta cinco tópicos — divididos em vários subtópicos —, que tratam da natureza, formas, funções, empregos e particularidades de emprego de pronomes pessoais. É válido destacar que os dados apresentados pela autora para exemplificar sua abordagem são ocorrências linguísticas de textos reais.

No primeiro tópico, a natureza dos pronomes pessoais, Neves (2000) afirma que os pronomes pessoais têm um caráter fórico, ou seja, são capazes de fazer referência pessoal no texto. No caso da terceira pessoa, essa referência ocorre tanto de maneira anafórica — a algo que já foi mencionado - quanto catafórica - a algo que será mencionado. De acordo com a linguista, quando a referência é à primeira ou segunda pessoa, é exofórica ou dêitica, pois remete a um dos interlocutores.

Ao fazer essa exposição, Neves (2000) apresenta exemplos para ilustrar as funções referenciais dos pronomes pessoais. Além disso, a autora observa que, em alguns casos raros, o pronome de terceira pessoa pode fazer referência a alguém dentro da situação de comunicação; e que os pronomes de primeira e segunda pessoa são recuperáveis no discurso direto. Para finalizar esse tópico, Neves (2000) destaca que os pronomes pessoais são os únicos que têm a capacidade de identificar puramente a pessoa gramatical, ao contrário dos possessivos e demonstrativos, que, além de identificarem a pessoa gramatical, fazem outra relação. 
No tópico seguinte, as formas dos pronomes pessoais, a linguista apresenta um quadro para evidenciar que os pronomes pessoais referenciam as três pessoas gramaticais, tanto no singular quanto no plural:

Quadro 3: Formas dos pronomes pessoais na Gramática Científica de Neves (2000)

\begin{tabular}{|l|l|l|}
\cline { 2 - 3 } \multicolumn{1}{c|}{} & \multicolumn{1}{c|}{ SINGULAR } & \multicolumn{1}{c|}{ PLURAL } \\
\hline $1^{\mathrm{a}}$ pessoa & Eu & Nós \\
\hline $2^{\mathrm{a}}$ pessoa & tu, você & vós, vocês \\
\hline $3^{\mathrm{a}}$ pessoa & ele, ela & eles, elas \\
\hline
\end{tabular}

Fonte: Neves (2000, p. 450)

É importante destacar que Neves (2000) considera as formas você e vocês como pronomes pessoais de $2^{a}$ pessoa, o que não é feito pela Gramática Tradicional nem pelo Livro Didático, que consideram você(s) como pronome de tratamento. Ela comenta, também, que as formas de terceira pessoa sofrem flexão de gênero. Em seguida, Neves (2000) apresenta quadros para demonstrar a distinção entre as formas tônicas, que ocorrem como sujeitos de verbos em forma finita, e átonas, "que não exercem essa função, para as três pessoas, e para singular e plural" (NEVES, 2000, p. 451):

Quadro 4: Pronomes pessoais que não exercem a função de sujeito na Gramática Científica de Neves (2000)

a) formas átonas

\begin{tabular}{|c|c|c|c|c|}
\hline & \multicolumn{2}{|c|}{ SINGULAR } & \multicolumn{2}{|c|}{ PLURAL } \\
\hline $1^{\mathrm{a}}$ pessoa & me $\left(^{*}\right)$ & & $\operatorname{nos}(*)$ & \\
\hline $2^{\mathrm{a}}$ pessoa & te $(*)$ & & $\operatorname{vos}(*)$ & \\
\hline $3^{\mathrm{a}}$ pessoa & $\mathrm{o}, \mathrm{a}$, lhe $(* * *)$ & se $(* *)$ & os, as, lhes $(* * *)$ & se $(* *)$ \\
\hline
\end{tabular}

(*) formas reflexivas ou não-reflexivas

$\left({ }^{* *}\right)$ formas reflexivas

$\left({ }^{* *}\right)$ formas não-reflexivas

b) formas tônicas

\begin{tabular}{|l|l|l|}
\cline { 2 - 3 } \multicolumn{1}{c|}{} & \multicolumn{1}{c|}{ SINGULAR } & \multicolumn{1}{c|}{ PLURAL } \\
\hline $1^{\text {a }}$ pessoa & mim, comigo $\left(^{*}\right)$ & nós, conosco $\left(^{*}\right)$ \\
\hline $2^{\text {a }}$ pessoa & ti, contigo $\left(^{*}\right)$ & vós, convosco $\left(^{*}\right)$ \\
\hline $3^{\text {a }}$ pessoa & si, consigo $\left(^{*}\right)$ & si, consigo $\left(^{* *}\right)$ \\
\hline
\end{tabular}

$\left(^{*}\right)$ formas reflexivas ou não-reflexivas

${ }^{* *}$ formas reflexivas

Fonte: Neves (2000, p. 451)

Conforme mostram os quadros acima, algumas dessas formas são reflexivas, as quais, segundo a autora, correferenciam o sujeito, isto é, são um complemento da mesma pessoa do 
sujeito. Neves (2000) acrescenta que as formas de plural que podem ser reflexivas são, também, recíprocas, visto que cada um dos termos (o sujeito e o complemento) representa os dois termos da relação transitiva.

No tópico seguinte, Neves (2000) expõe as funções dos pronomes pessoais, que são basicamente duas: interacional (remeter à situação de fala) e textual (garantir a continuidade do texto). Além dessas duas funções básicas, segundo a linguista, os pronomes pessoais têm uma função especial na oração, a saber, explicitar a natureza temática do referente. Essa função diz respeito ao papel que as formas de pronomes pessoais exercem sintaticamente nas sentenças: eu e tu, por exemplo, são restritos à função de sujeito, ao passo que as formas oblíquas átonas, por sua vez, são restritas a funções completivas, tendo formas particulares para objeto direto e indireto. Esse comentário equivale à categorização dos pronomes em reto e oblíquo, apresentada pela Gramática Tradicional e pelo Livro Didático e omitida na Gramática Científica.

Após essa exposição, a autora discorre a respeito de outra função básica dos pronomes pessoais, qual seja, referenciar os interlocutores da enunciação, por meio de primeira (aquela de quem parte o discurso), segunda (aquela a quem se dirige o discurso) e terceira (aquela sobre a qual é o discurso) pessoas. Neves (2000) destaca que haveria dois eixos envolvidos nesse quesito: um eixo subjetivo, ao qual pertencem o locutor e receptor da interação, e um eixo não subjetivo, do qual fazem parte as pessoas/coisas que não participam da interação (a terceira pessoa, que pode ser determinada ou indeterminada).

No quarto tópico, Neves (2000) expõe os empregos dos pronomes pessoais. Inicialmente, a linguista já apresenta um aspecto diferente da Gramática Tradicional, ao reconhecer que as formas você(s), que fazem concordância com o verbo na $3^{\mathrm{a}}$ pessoa, são muito mais comumente usadas para se referir à $2^{a}$ pessoa do que tu. Além disso, segundo ela, muitas vezes, há uma mistura nas formas de referência pessoal de segunda e de terceira pessoa, como, por exemplo, o uso de te peço e você é para fazer referência à mesma pessoa da oração. Neves (2000) comenta que, no caso dos pronomes pessoais do plural, faz-se referência a indivíduos que desempenham diferentes papéis no discurso. Outro emprego a respeito do qual a autora comenta é a referenciação genérica feita por alguns pronomes pessoais (você, eu, eles, dentre outras formas de indeterminação do sujeito).

Por fim, Neves (2000) aborda as particularidades no emprego de pronomes pessoais. Ela discute casos como as formas comigo, contigo, consigo, conosco e convosco, que representam a união dos pronomes pessoais à preposição com. A autora discorre, também, sobre a contração dos pronomes oblíquos lhe, me e te ao se juntarem com $o$, transformando-se em lho, mo e to, em registros formais. Outra particularidade é o chamado pleonasmo do objeto, em que o pronome oblíquo tônico reforça o pronome oblíquo átono da mesma pessoa. Neves (2000) comenta, ainda, que algumas formas oblíquas reflexivas são parte integrante dos chamados verbos pronominais, como admirar-se e decepcionar-se. Finalmente, a linguista apresenta o sintagma nominal a gente como pronome pessoal, na linguagem coloquial, que pode se referir à primeira pessoa do plural ou fazer referência genérica, indeterminando o sujeito.

Conforme pontua Anjos (2016), por um lado, o cenário dos estudos gramaticais na escola é extremamente favorável à inserção e recepção da Gramática de Usos do Português, uma vez que a obra tentou captar "a língua viva, funcionando e, assim, exibindo todas as possibilidades de composição que estão sendo aproveitadas pelos usuários para obtenção do sentido desejado 
em cada instância” (NEVES, 2000, p. 13). Por outro lado, pelo fato de realizar uma densa descrição da língua, valendo-se de uma metalinguagem muito especializada, a Gramática de Usos parece, até o momento, não ter conseguido alcançar as práticas de sala de aula do professor do Ensino Básico, ficando restrita, na prática, a estudantes de Letras do Ensino Superior.

\section{DISCUSSÃO: ANÁLISE COMPARATIVA DOS MATERIAIS E SUAS IMPLICAÇÕES PARA O ENSINO DE LÍNGUA PORTUGUESA}

A comparação entre a Gramática Tradicional, o Livro Didático e a Gramática Científica demonstra que as definições de pronome descritas por Cunha e Cintra (2001) e De Nicola (2005) são semelhantes. Nessas duas obras, os pronomes, considerados como classes de palavras, são definidos como palavras que representam/substituem os substantivos ou os acompanham/determinam, logo, podem ser classificados como pronomes substantivos ou pronomes adjetivos. Os pronomes são, também, categorizados, por esses autores, em seis tipos: pessoais, possessivos, demonstrativos, relativos, interrogativos e indefinidos. Essa categorização dos pronomes está em consonância com a proposição da NGB (BRASIL, 1958). Entretanto, essa classificação não é adotada na Gramática Científica por Neves (2000), que não apresenta uma definição para pronome, em geral, o que pode ser justificado pelo próprio agrupamento que a autora faz das classes de palavras, que coloca os diferentes tipos de pronomes como integrantes de diferentes processos que ocorrem na língua.

No que diz respeito à definição de pronome pessoal, todas as obras observadas citam basicamente os mesmos aspectos: a capacidade de identificar a pessoa gramatical e a de fazer referência no texto, ao substituir um nome. Todos os autores reconhecem, portanto, que as funções principais do pronome pessoal são a de identificar a pessoa gramatical (quem fala, com quem se fala e de que se fala) e a de referenciar algum elemento (um sintagma nominal) já mencionado. No entanto, de todas as obras, a de Neves (2000) é a que melhor explicita essas funções, visto que, ao partir de textos produzidos em condições reais, a autora consegue estabelecer que as funções dessa classe de palavras se resumem a duas: função interacional e função textual. Ou seja, a Gramática de Usos do Português, dentre as obras analisadas, é a que aborda, de maneira mais explícita, que os pronomes pessoais de $1^{\mathrm{a}}$ e $2^{\mathrm{a}}$ pessoa têm uma função dêitica/exofórica - visto que remetem às pessoas do discurso - e que os de $3^{\mathrm{a}}$ pessoa — também chamada de não-pessoa — têm função exofórica (anafórica ou catafórica) — uma vez que remetem a elementos da cadeia textual.

A divisão em pronomes pessoais retos (sujeito) e oblíquos (complemento) é feita, de forma explícita, na Gramática Tradicional e no Livro Didático, que utilizam essa terminologia, ao passo que, na Gramática Científica, há comentários a respeito da restrição das funções exercidas por determinados pronomes, porém, sem o uso do termo reto para se referir a pronomes que se referem ao sujeito da oração. Neves (2000) apresenta informações mais detalhadas do que as dos outros autores, visto que não se limita a mostrar um quadro com as formas e terminologias dos pronomes e discorre, separadamente, sobre cada um deles, nas diferentes funções. Além disso, os pronomes reflexivos são abordados nas Gramáticas analisadas, mas não no Livro Didático. Os pronomes recíprocos, por sua vez, são mencionados por Cunha e Cintra (2001), como também por Neves (2000), mas não por De Nicola (2005). 
Em relação aos exemplos apresentados em cada obra para ilustrar a exposição dos pronomes pessoais, pode-se afirmar que, de forma geral, Cunha e Cintra (2001) apresentam exemplos da literatura considerada como clássica, além de frases criadas por eles, assim como faz De Nicola (2005). Ou seja, os autores da Gramática Tradicional, assim como o do Livro Didático, baseiam-se em frases criadas por eles, apesar de De Nicola (2005) destacar e considerar a importância de partir de textos produzidos em contextos reais de produção e circulação. A abordagem de Neves (2000) é, nesse sentido, totalmente diferente, visto que a linguista parte de frases encontradas em textos produzidos em contextos reais, nos quais o uso da língua se dá de forma concreta. Ou seja, enquanto os autores que se baseiam na NGB partem das regras para criar os exemplos, a autora, que se baseia na linguística de cunho funcionalista, parte do uso para, assim, estabelecer as regras.

Ademais, pode-se afirmar que o caráter prescritivo da Gramática de Cunha e Cintra (2001) fica evidente, pois os autores consideram usos “errados” dos pronomes na língua. De Nicola (2005), no livro didático, por sua vez, comenta a respeito de determinados usos fora do padrão, mas não entra na questão de erro ou acerto, explicitamente. Neves (2000), em sua Gramática Científica de caráter funcionalista, baseia-se em usos da língua no momento de descrever as regras de funcionamento do português, sem fazer prescrições. É importante destacar que a autora considera a relevância do contexto sociocomunicativo para estabelecer as regras, comentando que determinados usos são restritos a um contexto formal, literário ou religioso, por exemplo. Logo, na obra de Neves (2000), as funções dos pronomes pessoais só são elencadas após serem analisadas em diferentes (con)textos, o que torna a abordagem da Gramática Científica mais rica e baseada em contextos reais de uso, ao contrário das outras obras analisadas.

Destacamos, no entanto, que o livro didático também apresenta a importância do contexto para a compreensão do funcionamento da classe de palavras conhecida como pronome pessoal. Ou seja, dentre as obras de abordagem prescritiva, o Livro Didático de De Nicola (2005) define a classe gramatical de maneira mais crítica, se comparado à Gramática de Cunha e Cintra (2001). Assim, notamos um impasse na proposta do Livro Didático: ao mesmo tempo em que se pauta nas proposições da Gramática Tradicional, o autor busca promover uma reflexão acerca dos pronomes, não se limitando à definição e exemplificação feitas na Gramática Tradicional. Da mesma maneira, apesar de os exercícios serem apresentados de maneira desarticulada com a apresentação prévia do conteúdo no livro, deve-se destacar que De Nicola (2005) utiliza exemplos concretos de usos linguísticos em gêneros textuais como a tirinha. Dessa forma, o livro didático, embora se baseie inicialmente nas prescrições das Gramáticas Tradicionais, também didatiza princípios teóricos da Linguística, tal como o conceito de foricidade, exemplificando-o e efetuando, com isso, o que é sugerido pelos estudiosos da língua, como a própria Neves (2000), que sugere que o texto seja o ponto de partida para ensino da Gramática.

\section{CONSIDERAÇÕES FINAIS}

Retomando as três etapas da abordagem da(s) Gramática(s) no ensino de Língua Portuguesa propostas por Savioli (2014), manuais gramaticais elaborados por filólogos, como o de Cunha e Cintra (2001), pertenceriam à primeira etapa. Apesar de preverem, na introdução da obra, a necessidade de se descrever a diversidade da Língua Portuguesa, a obra acaba por focalizar 
a questão dos rótulos atribuídos às categorias gramaticais, limitando-se a prescrições de uso da língua. Conforme reflexões promovidas por Neves (2002, p. 30), a Gramática Tradicional “apresenta uma tensão em dois planos”: apesar de não haver marcas explícitas de injunção, que corresponderia a um esquema neutro de apresentação das categorias, essas Gramáticas trabalham com o critério de “exemplaridade das amostras”. Dessa forma, a abordagem de exemplos que se limitam ao domínio da frase, preferencialmente a frases retiradas da literatura clássica, demonstram a adoção de "um parâmetro que se oferece como modelo", tal como apontado por Neves (2002, p. 31).

Considerando, especificamente, os materiais analisados, constatamos que, para uso em sala de aula, o livro didático de José de Nicola (2005) apresenta uma abordagem mais contextualizada dos pronomes pessoais do que a gramática de Cunha e Cintra (2001). Ressaltamos, porém, que certos aspectos na gramática de Neves (2000) - como a questão de utilizar textos provenientes de situações reais de produção como ponto de partida e considerar todos os usos linguísticos, explicando que algumas variantes são mais adequadas em determinados contextos, por exemplo - podem enriquecer a abordagem das classes de palavras em sala de aula. Segundo Lima (2016), a Gramática de Usos da Língua Portuguesa contribui, então, nas primeiras décadas do século XXI, para confirmar as conclusões dos estudiosos da gramaticografia brasileira, que possibilitam a desconstituição das bases da tradição gramatical.

Apesar da importância inegável da obra, para o professor do Ensino Básico, a ausência de transposições didáticas dessa e de outras Gramáticas Científicas para os Livros Didáticos de Língua Portuguesa, assim como a necessidade de domínio da teoria sociofuncionalista ou mesmo de outras teorias linguísticas, é um desafio, senão uma barreira à adoção dessas Gramáticas no contexto de sala de aula. A partir dessa constatação, notamos que, ainda hoje, há ressonâncias de problemas apontados por Savioli (2014) em relação à segunda etapa da abordagem gramatical no ensino de Língua Portuguesa. Isso sinaliza a necessidade de que as Gramáticas produzidas por linguistas sejam viabilizadas de maneira mais pedagógica, de modo a ir ao encontro das necessidades dos professores que atuam no Ensino Básico.

Uma relevante contribuição das Gramáticas Científicas, bem como dos documentos oficiais relativos à avaliação de Livros Didáticos de Língua Portuguesa, elaborados majoritariamente por profissionais provenientes de Instituições Públicas de Ensino Superior, diz respeito à responsabilidade da escola pelo ensino da variedade culta da Língua Portuguesa. Nesse sentido, mostram-se bastante profícuas as reflexões promovidas por Neves (2002, p. 46), segundo a qual “a própria proposição da norma de prestígio já formularia mais como uma orientação para adequação sociocultural de uso do que como uma receita de 'legitimidade' e de 'pureza' linguística de determinadas construções”.

Sendo assim, ao invés de o método de ensino gramatical limitar-se ao fornecimento de etiquetas linguísticas, esse ensino deve propiciar a imersão dos aprendizes, por meio de textos e gêneros textuais em que circula a variedade culta da língua, especialmente na modalidade escrita. Desse modo, o contato prolongado e reflexivo com essa variedade da língua viabiliza seu domínio por estudantes da Educação Básica. Concluímos, portanto, que não há um método ou manual gramatical definitivo para o ensino e aprendizagem de Língua Portuguesa, mas, sim, obras mais ou menos adequadas a esse fim, que se complementam e podem ser utilizadas, em 
conjunto, no ensino dos pronomes pessoais, tal como ilustramos, como também no ensino de outros conteúdos gramaticais de Língua Portuguesa.

\section{REFERÊNCIAS}

ANJOS, M. A. Gramática da língua portuguesa padrão: (des)continuidades? In: FARACO, C. A.; VIEIRA, F. E. (org.) Gramáticas brasileiras: com a palavra, os leitores. São Paulo: Parábola, 2016, p.187-214.

BRASIL. Ministério da Educação e Cultura. Nomenclatura Gramatical Brasileira. Rio de Janeiro, 1958.

BRASIL. Ministério da Educação. Parâmetros Curriculares Nacionais: Ensino Médio. Brasília: MEC/Secretaria de Educação Básica, 1999.

BRASIL. Ministério da Educação. Fundo Nacional de Desenvolvimento da Educação (FNDE). Panfleto Informativo do Programa Nacional do Livro Didático (PNLD). Brasília, DF: FNDE, abr. 2002.

BRASIL. Ministério da Educação. Fundo Nacional de Desenvolvimento da Educação (FNDE). Programa Nacional do Livro Didático de Ensino Médio (PNLEM). Brasília, DF: FNDE, 2004.

BRASIL. Ministério da Educação. Fundo Nacional de Desenvolvimento da Educação (FNDE). Língua Portuguesa. Catálogo do Programa Nacional do Livro para o Ensino Médio. Brasília, DF: FNDE, 2009.

BRASIL. Ministério da Educação. Base Nacional Comum Curricular: Ensino Médio. Brasília: MEC/Secretaria de Educação Básica, 2018.

CASTILHO, A. T. Reorganização do quadro dos pronomes pessoais: alteração, criação, substituição e perda. In: Gramática do Português Brasileiro. São Paulo: Contexto, 2010, p. 478-479.

CUNHA, C.; CINTRA, L. F. L. Nova Gramática do Português Contemporâneo. 3. ed. Rio de Janeiro: Nova Fronteira, 2001.

DE NICOLA, J. Português: ensino médio, volume 2. São Paulo: Scipione, 2005.

FIGUEIREDO SILVA, M. A posição sujeito no Português Brasileiro - frases finitas e infinitivas. Campinas: EdUNICAMP, 1996.

HENRIQUES, C. C. Nomenclatura gramatical brasileira: 50 anos depois. São Paulo: Parábola, 2009.

LIMA, A. Gramática de usos do português: metalinguagem em função. In: FARACO, C. A.; VIEIRA, F. E. (org.) Gramáticas brasileiras: com a palavra, os leitores. São Paulo: Parábola, 2016, p. 215-236.

NEVES, M. H. M. Gramática de usos do português. São Paulo: Editora UNESP, 2000.

NEVES, M. H. M. Que gramática ensinar na escola? São Paulo: Contexto, 2002. 
SAVIOLI, F. P. O percurso das gramáticas nas ações escolares. In: NEVES, M. H. M.; CASSEB-GALVÃO, V. C. (org.) Gramáticas brasileiras: com a palavra, os autores. São Paulo: Parábola, 2014, p. 134-152.

SILVA, M. A. A fetichização do livro didático no Brasil. Educação \& Realidade. Porto Alegre: v. 37, n. 3, 2012, p. 803-821. Disponível em: https://www.scielo.br/pdf/edreal/v37n3/06.pdf. Acesso em: 12 jul. 2020.

Recebido em: jul. 2020.

Aceito em: nov. 2020. 